\title{
Qualidade microbiológica de linguiças de frango do tipo frescal comercializadas no Distrito Federal, Brasil
}

Microbiological quality of fresh chicken sausages marketed in the Federal District, Brazil

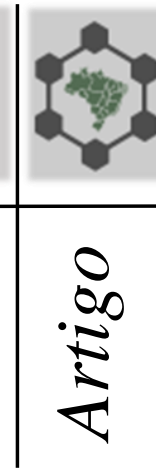

\section{Sabrina Lunara Santos Pavelquesi ${ }^{1}$, Bruna Ianka Bernardes de Jesus Gomes ${ }^{1}$, Stephanie Ramos Franca ${ }^{1}$, Izabel Cristina Rodrigues da Silva ${ }^{1}$, Daniela Castilho Orsi ${ }^{1 *}$}

Resumo: As linguiças frescais estão entre os embutidos cárneos mais consumidos pela população brasileira devido ao preço acessível. Esse estudo avaliou a qualidade microbiológica de linguiças de frango frescais comercializadas no Distrito Federal. As análises realizadas foram: contagem total de bactérias mesófilas e psicrotróficas, determinação de coliformes totais e coliformes termotolerantes, contagem de Staphylococcus aureus e pesquisa de Salmonella spp. Os resultados mostraram que das 16 amostras de linguiça de frango analisadas, 10 amostras $(62,5 \%)$ estavam impróprias para o consumo de acordo com a legislação brasileira, sendo que 9 amostras $(56,3 \%)$ apresentaram elevada contagem de microrganismos mesófilos $(>6,0 \mathrm{log} \mathrm{UFC} / \mathrm{g})$ e 4 amostras $(25,0 \%)$ estavam contaminadas com Salmonella spp. As bactérias Salmonella spp. foram geneticamente confirmadas através da detecção de gene Inva por PCR. Das 16 amostras de linguiça de frango analisadas neste estudo, 9 amostras $(56,3 \%)$ estavam contaminadas por bactérias $S$. aureus (confirmadas geneticamente através da detecção de gene $N u c$ por PCR), sendo que 3 amostras $(18,8 \%)$ apresentaram elevada contagem dessas bactérias (3,9-4,0 log UFC/g). Assim, o uso de matérias primas contaminadas, a falta de higiene durante o processamento e o armazenamento inadequado da linguiça frescal comprometem a sua qualidade e podem trazer risco a saúde do consumidor, pois a presença de bactérias patogênicas pode causar doenças de origem alimentar.

Termos para indexação: linguiça de frango; contaminação de alimentos; Salmonella.

Abstract: Fresh sausages are one of the meat products most consumed by the Brazilian population due to their affordable price. This study evaluated the microbiological quality of fresh chicken sausages marketed in the Federal District. The analyzes performed were: total count of mesophilic and psychrotrophic bacteria, determination of total coliforms and thermotolerant coliforms, count of Staphylococcus aureus and research of Salmonella spp. The results showed that of the 16 samples of chicken sausage analyzed, 10 samples $(62.5 \%)$ were unfit for consumption according to Brazilian legislation, with 9 samples (56.3\%) showing a high count of mesophilic microorganisms ( $>6.0 \mathrm{log}$ CFU / g) and 4 samples $(25.0 \%)$ were contaminated with Salmonella spp. The bacteria Salmonella spp. were genetically confirmed by detection of the Inva gene by PCR. Of the 16 samples of chicken sausage analyzed in this study, 9 samples $(56.3 \%)$ were contaminated by $S$. aureus bacteria (confirmed genetically through the detection of $N u c$ gene by PCR), and 3 samples (18.8\%) presented high count of these bacteria (3.9-4.0 log CFU/g). Thus, the use of contaminated raw materials, the lack of hygiene during processing and the inadequate storage of fresh sausages compromises their quality and may pose a risk to consumer health, as the presence of pathogenic bacteria can lead to food-borne diseases. 
Pavelquesi et al., Revista Brasileira de Higiene e Sanidade Animal (v.15, n.2) p. 1 - 12 abr - jun (2021)

Index terms: chicken sausage; food contamination; Salmonella.

\section{http://dx.doi.org/}

Autor para correspondência. E-mail: danielacastilhoorsi@gmail.com

Recebido em 16.02.2021. Aceito em 30.06.2021

1 Aluna de Mestrado em Ciências e Tecnologias da Saúde (UNB/FCE) - email: sabrinalunara@gmail.com

${ }^{2}$ Aluna de Graduação em Farmácia (UNB/FCE) - email: brunaiankaa@ gmail.com

${ }^{2}$ Aluna de Graduação em Farmácia (UNB/FCE) - email: stephaninh@ gmail.com

${ }^{3}$ Professora na Universidade de Brasília (UNB/FCE), Laboratório de Controle de Qualidade email: belbiomedica@gmail.com

${ }^{3}$ Professora na Universidade de Brasília (UNB/FCE), Laboratório de Controle de Qualidade, Centro Metropolitano, Conjunto A, lote 01, Ceilândia, CEP: 72220-900, Brasília, DF, Brasil.* Autor para correspondência email: danielacastilhoorsi@gmail.com

\section{Introdução}

As linguiças frescais, também conhecidas como linguiças do tipo frescal, estão entre os produtos embutidos mais consumidos pela população brasileira devido ao preço acessível (CORREIA et al., 2014). As carnes mais utilizadas na produção dessas linguiças são de porco e de frango (CABRAL et al., 2014). O consumo de produtos contendo carne de frango como hambúrgueres, salsichas, nuggets, almôndegas e linguiças, aumentou nas últimas décadas, como resultado dos investimentos da indústria de alimentos em processar a carne de frango para prolongar sua vida útil (SHARMA et al., 2017).

A linguiça frescal é um produto embutido curado e cru, portanto, não sofre nenhum processo de cozimento durante sua produção e apresenta alta atividade de água. Assim, esse produto tem um prazo de validade limitado e deve ser mantido em temperatura de refrigeração. As linguiças frescais são produtos perecíveis, pois são fabricadas a partir de carne moída fresca, assim, são favoráveis ao desenvolvimento de microrganismos deterioradores e patogênicos e têm um alto teor de gordura favorável à oxidação lipídica (ALBERTI e NAVA, 2014; CABRAL et al., 2014; EDDRA et al., 2018; HUGO e HUGO, 2015)

As prováveis fontes de contaminação microbiológica da linguiça frescal compreendem as carnes, os envoltórios, os condimentos, a manipulação, as máquinas, os utensílios, bem como a água utilizada em todas as operações do processamento (BEZERRA et al., 2012).

O processo de produção da linguiça frescal envolve várias etapas de manipulação do produto e caso essas 
Pavelquesi et al., Revista Brasileira de Higiene e Sanidade Animal (v.15, n.2) p. 1 - 12 abr - jun (2021)

etapas não sejam realizadas corretamente aumenta-se a chance de contaminação microbiológica por bactérias patogênicas, comprometendo a qualidade do produto (ED-DRA et al., 2018; VALIATTI et al., 2016).

A qualidade final da linguiça frescal também é dependente das temperaturas usadas para manter a cadeia de frio. Vários estágios da cadeia de frio, como transporte e salas de estocagem representam pontos críticos para os produtores. Varejistas nem sempre conseguem manter adequada à cadeia de frio, o que acarreta aumento dos riscos microbiológicos para produtos cárneos como a linguiça frescal (SOUZA, 2014).

O aumento da produção e do consumo de linguiça frescal faz com que surja uma preocupação em relação à segurança alimentar desse produto, visto que tais embutidos podem ser veiculadores de microrganismos causadores de doenças transmitidas por alimentos como Salmonella spp., Escherichia coli O157:H7 e Staphylococcus aureus (ED-DRA et al., 2018; MERLINNI et al., 2012). Sendo assim, este trabalho teve como objetivo avaliar a qualidade microbiológica de linguiças de frango do tipo frescal comercializadas no Distrito Federal.

\section{Material e Métodos \\ Coleta, preparo das amostras e análises microbiológicas}

Foram coletadas dezesseis amostras de linguiças de frango do tipo frescal de diferentes marcas comerciais, dentro do prazo de validade e expostas ao consumo nos balcões refrigerados, em diferentes supermercados do Distrito Federal. Todas as amostras foram analisadas em três repetições, ou seja, foram retiradas três alíquotas de cada embalagem. Para o preparo das amostras, foram pesadas $25 \mathrm{~g}$ em $225 \mathrm{~mL}$ de água peptonada $0,1 \%(\mathrm{p} / \mathrm{v})$. O material foi homogeneizado, obtendo-se desta forma a primeira diluição $\left(10^{-1}\right)$. A partir da primeira diluição obtiveram-se as demais diluições decimais (até $10^{-4}$ ).

Para a contagem total de bactérias mesófilas e psicrotróficas, as diluições de cada amostra foram semeadas, pelo método de superfície, no meio de cultivo Ágar Padrão para Contagem. As placas foram incubadas a $37^{\circ} \mathrm{C}$ por $24 \mathrm{~h}$ para bactérias mesófilas e a $7^{\circ} \mathrm{C} \pm 1^{\circ} \mathrm{C}$ por 7 dias para bactérias psicrotróficas.

Para a determinação do Número Mais Provável (NMP) de coliformes totais e de coliformes termotolerantes, as amostras foram analisadas conforme a técnica de tubos múltiplos, iniciando-se 
com o teste presuntivo, que consiste na inoculação de cada diluição das amostras em caldo Lauril Sulfato Triptose. Os tubos foram incubados a $37^{\circ} \mathrm{C}$ por $24 \mathrm{~h}$. A positividade do teste caracterizou-se pela turvação do caldo com a produção de gás nos tubos de Durham. Alíquotas dos tubos positivos no teste presuntivo foram inoculadas, simultaneamente, em tubos de ensaio contendo caldo verde brilhante bile lactose a $2 \%$ (para a confirmação de coliformes totais) e caldo Escherichia coli (para a confirmação de coliformes termotolerantes). Os tubos foram incubados em estufa bacteriológica a $37^{\circ} \mathrm{C}$ por $24 \mathrm{~h}$ para o teste de coliformes totais e em banho-maria a $45^{\circ} \mathrm{C}$ por $24 \mathrm{~h}$ para o teste de coliformes termotolerantes.

Para a contagem de $S$. aureus, cada uma das diluições das amostras foi semeada, pelo método de superfície, no meio de cultivo Agar Sal Manitol. As placas foram incubadas a $37^{\circ} \mathrm{C}$ por $48 \mathrm{~h}$. As colônias isoladas suspeitas de $S$. aureus foram reisoladas em tubos de Agar Sal Manitol e submetidas à coloração de Gram e identificação molecular através da técnica de reação em cadeia da polimerase (PCR).

Todos os resultados obtidos foram expressos em média de $\log \mathrm{UFC} / \mathrm{g}$ ou média de log NMP/g. Para a pesquisa de Salmonella spp., a diluição $10^{-1}$ das amostras foi incubada à $37^{\circ} \mathrm{C}$ por $24 \mathrm{~h}$. Após a incubação, alíquotas do caldo de enriquecimento foram transferidas para tubos contendo $10 \mathrm{~mL}$ de caldo selenito cistina. As amostras foram homogeneizadas e incubadas a $37^{\circ} \mathrm{C}$ por 24 h. Após a incubação, procedeu-se à técnica de isolamento, onde a partir de cada tubo, semearam-se placas de Petri contendo o meio de cultivo Agar Xilose-LisinaDesoxicolato (XLD). As placas foram incubadas a $37^{\circ} \mathrm{C}$ por $24 \mathrm{~h}$. As colônias suspeitas de Salmonella spp. no XLD foram transferidas para tubos inclinados contendo o meio de cultivo Agar Três Açúcares e Ferro (TSI). Os tubos de TSI que apresentaram reações típicas de Salmonella foram submetidos às provas bioquímicas em Agar Lisina Ferro e Agar Fenilalanina. As cepas isoladas suspeitas de Salmonella spp. foram submetidas à identificação molecular por meio da técnica de PCR.

\section{Identificação molecular de S. aureus} e Salmonella spp.

Para extração do DNA, as colônias isoladas foram inoculadas, individualmente, em caldo Luria Bertani e incubadas a $37^{\circ} \mathrm{C}$ por $18 \mathrm{~h}$. A extração do DNA foi realizada de acordo com o protocolo proposto no kit comercial Plasmid DNA purification MACHEREYNAGEL ${ }^{\circledR}$. A qualidade e a quantidade de 
Pavelquesi et al., Revista Brasileira de Higiene e Sanidade Animal (v.15, n.2) p. 1 - 12 abr - jun (2021)

DNA extraídos foram determinadas por eletroforese em gel de agarose, em comparação com o padrão de massa molecular DNA1/HindIII marcador de 100 pb $\left(\right.$ JENA $\left.^{\circledR}\right)$. Após a extração do DNA, à amplificação de fragmentos de genes foi realizada utilizando o termociclador Techne ${ }^{\circledR}$ modelo TC-512. As condições de termociclagem foram $50^{\circ} \mathrm{C}$ por $2 \mathrm{~min}$., $95^{\circ} \mathrm{C}$ por 2 min. e 40 ciclos de desnaturação a $95^{\circ} \mathrm{C}$ por 15 seg., seguida de $60^{\circ} \mathrm{C}$ por $30 \mathrm{seg}$., para o anelamento dos oligonucleotídeos e $72^{\circ} \mathrm{C}$ por $30 \mathrm{seg}$. para a extensão dos fragmentos.

Foram utilizados $2,5 \mu \mathrm{L}$ de tampão (10 $\mathrm{mM}$ de Tris e $50 \mathrm{mM}$ de $\mathrm{KCl}$ ), 0,7 $\mu \mathrm{L}$ de $\mathrm{MgCl}_{2}, 1,5 \mu \mathrm{L}$ de dNTPs $(2,5 \mathrm{mM}), 0,5$ $\mu \mathrm{L}$ de Taq-Polimerase (Cenbiot $\left.{ }^{\circledR}, 5 \mathrm{U} / \mu \mathrm{L}\right)$,
1,5 $\mu \mathrm{L}$ de oligonucleotídeos foward e reverse $(10 \mu \mathrm{M})$, completando com água Milli-Q para um volume final de $25 \mu \mathrm{L}$ por reação, com a amplificação de $10 \mathrm{ng}$ de DNA extraído da amostra bacteriana. Os produtos de PCR foram submetidos à eletroforese em gel de agarose, contendo brometo de etídeo e visualizados sob iluminação ultra-violeta. O marcador de massa molecular utilizado foi o $100 \mathrm{pb}$ DNA1/HindIII $\quad\left(\right.$ JENA $\left.^{\circledR}\right)$. Para a identificação de Salmonella spp. foi utilizado o fragmento de 298 pares de base referente ao gene invA e para a identificação de $S$. aureus foi utilizado o fragmento de 105 pares de base referente ao gene Nuc (Tabela 1).

Tabela 1. Sequência dos primers e tamanho dos produtos amplificados na PCR para identificação dos genes invA e Nuc

\begin{tabular}{clcc}
\hline \multicolumn{1}{c}{ Primer } & \multicolumn{1}{c}{ Sequência 5' - 3' $^{\prime}$} & $\begin{array}{c}\text { Produto } \\
\text { amplificado }\end{array}$ & Bactéria \\
\hline invA foward & CTCGCCTTTGCTGGTTTTAG & $298 \mathrm{pb}$ & Salmonella spp. \\
invA reverse & CTCGCCTTTGCTGGTTTTAG & & \\
Nuc foward & TGTTTGTGATGCATTTGCTG & $105 \mathrm{pb}$ & S. aureus \\
Nuc reverse & AAAGGGCAATACGCAAAGAG & 105 & \\
\hline
\end{tabular}

\section{Resultados e Discussão}

Os resultados das análises microbiológicas das dezesseis amostras de linguiça de frango do tipo frescal analisadas no presente estudo estão apresentados na Tabela 2. A legislação brasileira (BRASIL, 2019) considera para produtos cárneos crus à base de carne moída ou picada de aves como linguiças frescais, como limite aceitável para microrganismos mesófilos valores que não excedam 6,0 $\log \mathrm{UFC} / \mathrm{g}$. No total das 16 
Pavelquesi et al., Revista Brasileira de Higiene e Sanidade Animal (v.15, n.2) p. 1 - 12 abr - jun (2021)

amostras de linguiça de frango analisadas neste estudo, 9 amostras $(56,3 \%)$ apresentaram elevada contagem de bactérias mesófilas com valores médios variando de 6,7 a 8,6 log UFC/g, e portanto, estavam impróprias para o consumo. Em relação as bactérias psicrotróficas, 7 amostras $\quad(43,8 \%)$ apresentaram elevadas contagens com valores médios variando de 6,6 a $8,3 \mathrm{log}$ $\mathrm{UFC} / \mathrm{g}$

Tabela 2. Análises microbiológicas das amostras de linguiça de frango do tipo frescal

\begin{tabular}{|c|c|c|c|c|c|c|}
\hline Amostras & $\begin{array}{c}\text { Bactérias } \\
\text { mesófilas } \\
(\log \\
\text { UFC/g) }\end{array}$ & $\begin{array}{c}\text { Bactérias } \\
\text { psicrotrófica } \\
\text { s } \\
\text { (log UFC/g) }\end{array}$ & $\begin{array}{c}\begin{array}{c}\text { Coliformes } \\
\text { totais }\end{array} \\
\text { (log NMP/g) }\end{array}$ & $\begin{array}{c}\text { Coliformes } \\
\text { termotolerante } \\
\mathrm{s} \\
(\log \mathrm{NMP} / \mathrm{g})\end{array}$ & $\begin{array}{c}\text { S. aureus } \\
(\log \mathrm{UFC} / \mathrm{g})\end{array}$ & $\begin{array}{c}\text { Salmonella } \\
\text { spp. }\end{array}$ \\
\hline 1 & $5,8 \pm 0,01$ & $5,8 \pm 0,01$ & $1,6 \pm 0,63$ & $0,2 \pm 0,01$ & $1,5 \pm 0,42$ & Ausência \\
\hline 2 & $5,3 \pm 0,11$ & $5,0 \pm 0,13$ & $1,7 \pm 0,50$ & $0,5 \pm 0,48$ & $4,0 \pm 0,06$ & Presença \\
\hline 3 & $4,8 \pm 0,24$ & $5,3 \pm 0,41$ & $2,4 \pm 0,72$ & $0,6 \pm 0,32$ & $3,9 \pm 0,05$ & Ausência \\
\hline 4 & $5,7 \pm 0,03$ & $5,1 \pm 0,05$ & $1,5 \pm 0,42$ & $0,4 \pm 0,38$ & $1,8 \pm 0,21$ & Ausência \\
\hline 5 & $2,8 \pm 0,22$ & $3,0 \pm 0,13$ & $1,2 \pm 0,89$ & $0,1 \pm 0,01$ & ND & Ausência \\
\hline 6 & $4,9 \pm 0,81$ & $6,6 \pm 0,01$ & $1,4 \pm 0,21$ & $0,1 \pm 0,01$ & $1,3 \pm 0,00$ & Ausência \\
\hline 7 & $7,2 \pm \mathbf{0 , 0 3}$ & $5,2 \pm 0,18$ & $3,1 \pm 0,00$ & ND & ND & Ausência \\
\hline 8 & $7,2 \pm 0,01$ & $5,8 \pm 0,02$ & $1,7 \pm 0,38$ & ND & $4,0 \pm 0,06$ & Ausência \\
\hline 9 & $7,5 \pm \mathbf{0 , 0 1}$ & $4,2 \pm 0,10$ & $1,9 \pm 0,43$ & $0,7 \pm 0,20$ & ND & Ausência \\
\hline 10 & $6,2 \pm 0,45$ & $7,0 \pm 0,17$ & $3,1 \pm 0,23$ & $0,9 \pm 0,45$ & ND & Presença \\
\hline 11 & $8,6 \pm 0,23$ & $7,4 \pm \mathbf{0 , 1 4}$ & $1,8 \pm 0,92$ & ND & ND & Ausência \\
\hline 12 & $8,2 \pm 0,37$ & $\mathbf{7 , 9} \pm \mathbf{0 , 0 5}$ & $3,1 \pm 0,01$ & $0,7 \pm 0,22$ & $0,7 \pm 0,99$ & Ausência \\
\hline 13 & $8,2 \pm 0,15$ & $\mathbf{7 , 8} \pm \mathbf{0 , 0 8}$ & $2,9 \pm 0,28$ & $0,2 \pm 0,40$ & $0,7 \pm 0,99$ & Ausência \\
\hline 14 & $8,2 \pm 0,06$ & $\mathbf{7 , 7} \pm \mathbf{0 , 7 2}$ & $2,4 \pm 0,80$ & $1,1 \pm 0,30$ & ND & Presença \\
\hline 15 & $3,9 \pm 0,11$ & $4,7 \pm 0,11$ & $2,6 \pm 0,17$ & $1,0 \pm 0,99$ & ND & Ausência \\
\hline 16 & $6,7 \pm 0,10$ & $8,3 \pm 0,20$ & $3,1 \pm 0,00$ & $1,1 \pm 0,99$ & $1,3 \pm 0,99$ & Presença \\
\hline
\end{tabular}

Os resultados foram expressos como médias \pm desvio padrão de três repetições; $\mathrm{ND}=$ não detectado 
No estudo de Sharma et al. (2017) foi observado um aumento significativo da contagem de microrganismos mesófilos em linguiças de frango frescais durante $o$ período de estocagem de 20 dias em temperatura de $4^{\circ} \mathrm{C}$, sendo que até os 10 dias de estocagem a contagem de microrganismos mesófilos se manteve abaixo de 6,0 log UFC/g e em 15 dias de estocagem essa contagem aumentou para 6,9 $\log$ UFC/g. Já no estudo de Serrano et al. (2018) das 39 amostras de linguiças frescais comercializadas na Suíça, 35 amostras $(89,7 \%)$ apresentaram contagem de bactérias mesófilas maior que 6,0 log $\mathrm{UFC} / \mathrm{g}$.

O estudo de Correia et al. (2014) mostrou um aumento da contagem de bactérias psicrotróficas em linguiças frescais de 2,7-2,8 log UFC/g (no tempo zero de estocagem) para 8,6-9,6 log UFC/g (em 10 dias de estocagem) a $7^{\circ} \mathrm{C}$. As bactérias psicrotróficas apresentam desenvolvimento em temperaturas de refrigeração, sendo capazes de deteriorar e diminuir a vida útil de alimentos refrigerados (BEZERRA et al., 2012).

A legislação brasileira (BRASIL, 2019) não estabelece um padrão microbiológico para enumeração de coliformes totais para a linguiça frescal, porém assim como as bactérias mesófilas e psicrotróficas, este grupo é um indicador da qualidade higiênico-sanitária dos alimentos (ALBERTI e NAVA, 2014; SERRANO et al., 2018). Neste estudo, 4 amostras $(25,0 \%)$ apresentaram condições insatisfatórias de higiene pelo elevado número de coliformes totais (acima de 3,0 $\log \mathrm{NMP} / \mathrm{g})$. No estudo de Silva et al. (2016) as amostras de linguiça frescal bubalina produzidas na Ilha do Marajó (Pará), apresentaram valores elevados de coliformes totais (acima de 3,0 log NMP/g) e segundo os autores esses resultados indicaram deficiências higiênicossanitárias no processamento dessas linguiças.

Para os coliformes termotolerantes a legislação brasileira (BRASIL, 2019) estabelece um limite de 3,7 log NMP/g para a linguiça de frango frescal. A presença de coliformes termotolerantes é indicativa de contaminação fecal direta ou indireta no alimento, sendo E. coli a principal bactéria representante desse grupo (ALBERTI e NAVA, 2014; SOUZA et al., 2014). Todas as amostras deste estudo apresentaram um número aceitável de coliformes termotolerantes: 13 amostras $(81,3 \%)$ com valores entre 0,1 e $1,1 \log$ $\mathrm{NMP} / \mathrm{g}$ e 3 amostras (18,8\%) não apresentaram coliformes termotolerantes.

Resultados semelhantes a este estudo foram reportados por Bezerra et al. (2012), onde as 28 amostras de linguiça frescal analisadas encontraram-se dentro dos limites aceitáveis para coliformes termotolerantes. Porém, outros estudos 
reportaram contagens mais elevadas de coliformes termotolerantes em amostras de linguiças frescais. No estudo de Merlinni et al. (2012), das 40 amostras de linguiça frescal analisadas, 20 amostras (50\%) apresentaram excesso de coliformes termotolerantes e estavam impróprias para o consumo. No estudo de Alberti e Nava (2014), observou-se que 67\% das linguiças frescais obtidas em supermercados no município de Xaxim (Santa Catarina) apresentaram valores insatisfatórios para coliformes termotolerantes. E no estudo de Souza et al. (2014), 16 amostras de linguiças frescais $(40 \%)$ comercializadas no oeste do Paraná estavam inaceitáveis para o consumo devido ao excesso de coliformes termotolerantes.

Das 16 amostras de linguiça de frango analisadas neste estudo, 9 amostras $(56,3 \%)$ estavam contaminadas por bactérias $S$. aureus, sendo que 3 amostras $(18,8 \%)$ apresentaram elevada contagem dessas bactérias $(3,9-4,0 \log \mathrm{UFC} / \mathrm{g})$. O limite permitido pela legislação brasileira era de 3,7 log UFC/g (BRASIL, 2001), porém com a recente atualização da legislação (BRASIL, 2019) não existe mais um limite microbiológico para S. aureus nas linguiças frescais.

No estudo de Valiatti et al. (2016), das 30 amostras de linguiças frescais analisadas comercializadas em supermercados do município de Ji-Paraná (Rondônia), 2 amostras (6,7\%) apresentaram contagem de $S$. aureus acima de 3,7 log UFC/g. A presença de bactérias S. aureus na linguiça frescal indica falta de higiene do manipulador, pois essa bactéria está comumente presente na microbiota humana. A bactéria $S$. aureus é transmitida aos alimentos principalmente pelas condições inadequadas de higiene, possibilitando também contaminações cruzadas por contato com equipamentos, utensílios e com a matéria-prima (SERRANO et al., 2018; VALIATTI et al., 2016). O estudo de Correia et al. (2014) avaliou o efeito da concentração de nitrito (50, 150 e 200 ppm) frente à contaminação proposital por $S$. aureus em linguiças frescais armazenadas a 7 e $12^{\circ} \mathrm{C}$ e estocadas por 10 dias. Os resultados demonstraram que em 10 dias de estocagem as contagens de S. aureus foram elevadas variando de 4,5 a 5,7 log UFC/g, mostrando que a temperatura de refrigeração e as concentrações de nitrito utilizadas não exerceram controle efetivo das bactérias $S$. aureus. A presença elevada de bactérias $S$. aureus nos alimentos pode causar risco a saúde, pois muitas cepas são produtoras de toxinas estafilocócicas termoresistentes e podem causar intoxicação alimentar no consumidor (SERRANO et al., 2018; VALIATTI et al., 
Pavelquesi et al., Revista Brasileira de Higiene e Sanidade Animal (v.15, n.2) p. 1 - 12 abr - jun (2021)

2016).

As bactérias $S$. aureus foram confirmadas nas amostras de linguiças de frango através da identificaçao do gene $N u c$, que codifica uma termonuclease produzida por $S$. aureus, sendo essencial para a sua patogênese e exclusivo para as bactérias dessa espécie (KIEDROWSKI et al., 2011).

A legislação brasileira (BRASIL, 2019) não permite a presença de Salmonella spp. em linguiças frescais. No presente estudo, 4 amostras $(25,0 \%)$ estavam contaminadas com Salmonella spp. e, portanto, estavam impróprias para o consumo.

Resultados similares foram reportados no estudo de Cabral et al. (2014), onde investigou-se a presença de Salmonella em 80 amostras de linguiças frescais de frango e de porco e a positividade foi de $26 \%$, sendo que os autores também utilizaram o gene InvA para a confirmação molecular de Salmonella spp.

Ainda nesse estudo, a embalagem original ou a embalagem nas bandejas de poliestireno realizada pelos supermercados não teve influência significativa nas taxas de contaminação dessas linguiças com Salmonella, sugerindo que a matéria prima contaminada e as práticas inadequadas de higiene durante o processo de fabricação são os principais fatores que aumentam a contaminação da linguiça frescal por Salmonella.

No estudo de Cavalin et al. (2018), Salmonella spp. foi isolada em 13 amostras $(28,3 \%)$ de linguiças frescais de porco e os autores sugeriram que a presença dessa bactéria nas amostras ocorreu devido a contaminação da planta de processamento e ou das matérias primas utilizadas na fabricação das linguiças.

Valiatti et al. (2016) reportaram que das 30 amostras de linguiças frescais comercializadas em Ji-Paraná, (Rondônia), 6 amostras (20\%) apresentaram Salmonella spp. A presença de Salmonella nos alimentos gera risco a saúde do consumidor, sendo essa bactéria entérica responsável por quadros frequentes de surtos de doenças alimentares no Brasil (DRAEGER et al., 2019).

As bactérias Salmonella foram confirmadas nas amostras de linguiças de frango através da identificaçao do gene $\underline{i n v A}$ que contém sequências exclusivas para esse gênero.

A presença do gene invA indica que a Salmonella possui um eficiente mecanismo de entrada e invasão do epitélio intestinal e essa invasão é um fator de virulência essencial no processo de infecção causado por tal patógeno, assim, o gene invA é reconhecido como padrão 
Pavelquesi et al., Revista Brasileira de Higiene e Sanidade Animal (v.15, n.2) p. 1 - 12 abr - jun (2021)

internacional para detecção de Salmonella

(MOURA, et. al., 2014;

\section{Conclusões}

Os resultados do estudo mostraram que das 16 amostras de linguiça de frango analisadas, 10 amostras $(62,5 \%)$ estavam impróprias para o consumo de acordo com a legislação brasileira, sendo que 9 amostras $(56,3 \%)$ apresentaram elevada contagem de microrganismos mesófilos $(>$ $6,0 \log \mathrm{UFC} / \mathrm{g})$ e 4 amostras $(25,0 \%)$ estavam contaminadas com Salmonella spp.

Em relação as bactérias $S$. aureus, 9 amostras (56,3\%) estavam contaminadas por essas bactérias, sendo que 3 amostras $(18,8 \%)$ apresentaram contagem elevada de $S$. aureus (3,9-4,0 log UFC/g).

Por ser um alimento amplamente consumido no Brasil, a cadeia produtiva das linguiças frescais deveria ser mais rigorosa em relação à qualidade das matérias primas, higiene na produção e manutenção da cadeia do frio, podendo com essas medidas minimizar a contaminação microbiana e melhorar a qualidade desse produto.

\section{AGRADECIMENTOS}

O presente trabalho foi realizado com apoio da Coordenação de Aperfeiçoamento de Pessoal de Nível Superior - Brasil (CAPES) - Código de Financiamento 001.
SHANMUGASAMY, et al., 2011).

\section{Referências Bibliográficas}

ALBERTI, J; NAVA, A. Avaliação higiênicossanitária de linguiças tipo frescal comercializadas a granel por supermercados e produzidas artesanalmente no município de Xaxim, SC. Unoesc \& Ciência, Joaçaba, v. 5, n. 1, p. 41-48, 2014.

BEZERRA, M.V.P.; ABRANTES, M.R.; SILVESTRE, M.K.S.; SOUSA, E.S.; ROCHA, M.O.C.; FAUSTINO, J.G.; SILVA, J.B.A. Avaliação microbiológica e físico-química de linguiça toscana no município de Mossoró, RN. Arquivos do Instituto Biológico, São Paulo, v. 79, n. 2, p. 297-300, 2012.

BRASIL, Agência Nacional Vigilância Sanitária (ANVISA). Instrução normativa $\mathrm{n}^{\circ}$ 60, de 23 de dezembro de 2019. Estabelece as listas de padrões microbiológicos para alimentos. 2019. Disponível em:

https://www.gov.br/agricultura/pt-

br/assuntos/inspecao/produtosvegetal/legislacao-1/biblioteca-de-normasvinhos-e-bebidas/instrucao-normativandeg-60-de-23-de-dezembro-de2019.pdf/view

BRASIL. Agência Nacional de Vigilância Sanitária. RDC no 12, de 02 de janeiro de 2001. Aprova o Regulamento sobre padrões microbiológicos para alimentos e seus anexos I e II. Diário oficial da República Federativa do Brasil, Brasília, DF, nº7 p. 45-53, de 10 de janeiro de 2001.

CABRAL, C.C.; CONTE-JUNIOR, C.A.; SILVA, J.T.; PASCHOALIN, V.M.F. Salmonella spp. contamination in fresh pork and chicken sausages marketed in Niterói and Rio de Janeiro, Brazil. Journal Für Verbraucherschutz Und Lebensmittelsicherheit, v. 9, n. 3, p. 243249, 2014. 
CAVALIN, P.B.B.; SARMIENTO, J.J.P.; KOBAYASHI, R.K.T.; NAKAZATO, G.; OCAÑA, A.N.; OLIVEIRA, T.C.R.M. Detection of Salmonella spp. and diarrheagenic Escherichia coli in fresh pork sausages. Semina: Ciências Agrárias, Londrina, v. 39, n. 4, p. 1533-1546, 2018.

CORREIA, L.M.M.; PEREIRA， J.G.; PINTO, J.P.A.N.; BARCELLOS, V.C.; BERSOT, L.S. Behavior of Staphylococcus aureus and autochthone microbiota in fresh sausages added of sodium nitrite and stored under refrigeration. Ciência Rural, Santa Maria, v. 44, n. 10, p. 1880-1885, 2014.

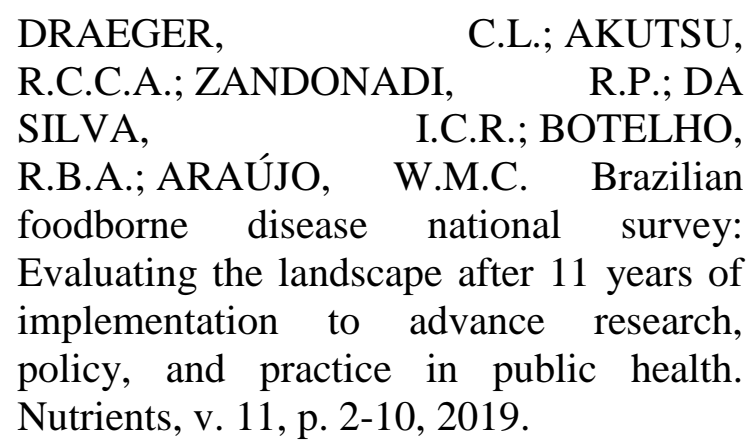

ED-DRA, A.; FILALI, F.R.; BOUYMAJANE, A.; BENHALLAM, F.; ALLAOUI, A.E.; CHAIBA, A.; GIARRANTANA, F. Antibiotic susceptibility profile of Staphylococcus aureus isolated from sausages in Meknes, Morocco. Veterinary World, v. 11, n. 10, p. 1459-1465, 2018.

HUGO, C.J.; HUGO, A. Current trends in natural preservatives for fresh sausage products. Trends in Food Science \& Technology, v. 45, n. 1, p. 12-23, 2015.

KIEDROWSKI, M.R.; KAVANAUGH, J.S.; MALONE， C.L.; MOOTZ，J.M.; VOYICH， J.M.; SMELTZER, M.S.; BAYLES, K.W.; HORSWILL, A.R. Nuclease modulates biofilm formation in community-associated methicillin-resistant Staphylococcus aureus. PLoS One, v. 6, n. 11, p. 1-16. 2011.
MERLINNI, L.S.; BEGOTTI, I.L.; MERLINI, N.B.; CAETANO, I.C.S. Avaliação higiênicossanitária de linguiças tipo frescal produzidas artesanalmente na região noroeste do Paraná. Centro Científico Conhecer, Goiânia, v. 8, n. 15, p. 344-352, 2012.

MOURA, M.S.; OLIVEIRA, R.P.; MELO, R.T.; MENDONÇA, E.P.; FONSECA, B.B.; ROSSI, D.A. Genes de virulência e diversidade genética em Salmonella spp. isoladas de amostras de origem suína. Arquivo Brasileiro

de Medicina Veterinária e Zootecnia, v.66, n.5, p.1367-1375, 2014.

SERRANO, N. S., SWEIFEL, C., CORTI, S. STEPHAN, R. Microbiological quality and presence of foodborne pathogens in raw milk cheeses and raw meat products marketed at farm level in Switzerland. Italian Journal of Food Safety, v. 7, p. 110-115, 2018.

SHANMUGASAMY, M.; VELAYUTHAM, T.; RAJESWAR, J. InvA gene specific PCR for detection of Salmonella from broilers. Veterinary World, v. 4, n. 12, p. 562-564, 2011.

SHARMA, H.; MENDIRATTA, S.K.; AGARWAL, R.K.; KUMAR, S.; SONI, A. Evaluation of antioxidant and antimicrobial activity of various essential oils in fresh chicken sausages. Journal of Food Science and Technology, v. 54, n. 2, p. 279-292, 2017.

SILVA, A.P.M.; BIBIANO, J.N.; PORTAL, R.S.; SILVA, J.C.C.; NEVES, I.D.L.; FIGUEIREDO, E.L. Avaliação microbiológica da linguiça artesanal bubalina produzida na Ilha do Marajó , Pará, Brasil. Scientia Plena, v. 12, n. 06, p. 1-6, 2016. 
SOUZA, S.A. Avaliação dos efeitos de diferentes temperaturas de congelamento e armazenamento sobre as características microbiológicas, físico-químicas e sensoriais de linguiça suína tipo frescal. 2014. 61 p. Tese (Mestrado em Engenharia de Alimentos), Engenharia de Alimentos, Universidade Regional Integrada do Alto Uruguai e das Missões, Erechim, RS, 2014.

SOUZA, M.; PINTO, F. G. S.; BONA, E. A. M.; MOURA, A. C. Qualidade higiênicossanitária e prevalência de sorovares de Salmonella em linguiças frescais produzidas artesanalmente e inspecionadas, comercializadas no oeste do Paraná, Brasil. Arquivos do Instituto Biológico, São Paulo, v.81, n.2, p. 107112, 2014.
VALIATTI, T.B.; BARCELOS, I.B.; CALEGARI, G.M.; SILVA, W.M.C.; ALMEIDA, F.K. V.; PRAZERES, P.F.L; SOBRAL, F.O.S.; ROMÃO, N.F.; GASPAROTTO, P.G.H. Avaliação microbiológica de linguiças tipo frescal comercializadas em supermercados do município de Ji-Paraná, Rondônia. Revista da Universidade Vale do Rio Verde, Três Corações, v. 14, n. 2, p. 678-686, 2016. 